\title{
Energy Efficiency Improvement of Debutanizer Column, for NGL Separation
}

\author{
Ahmed Ould Brahim and Souad Abderafi
}

\begin{abstract}
Compared to other petroleum, the natural gas combustion remains the cleanest and the one showing less $\mathrm{CO}_{2}$ emission. These reasons make the natural gas combustion one of the important issues to study. The separation of NGL is energy intensive. This operation is performed through a series of column including the debutanizer column. The present work is devoted to optimize the energy consumption at the level of the debutanizer column. The response surface technique and deploying a central composite numerical design is followed makes use of available data from a refinery. Using a multiple linear regressions, the optimization method leads us to three reliable models. Each of the three models takes as input the reflux ratio and the head pressure in order to predict the condenser heat duty, the reboiler heat duty and the purity of the produced butane. Suggested mathematical models were validated and their reliability was assessed via a set of statistical analyses. The optimization aims to simultaneously minimize the energy consumption of the condenser and reboiler, and maximize the purity of the ejected Butane. This optimization step allowed us to define the optimal values of reflux ratio and head pressure, with desirability function equal to $99 \%$. Under the determined optimal values, operating energy and cost of the industrial process were reduced by $38 \%$ and $37 \%$, respectively, and besides, a high purity of butane was noticed reaching $99 \%$. From an economic point of view, separation NGL with optimal values of pressure and reflux ratio, may contribute to a decrease of $\mathrm{CO}_{2}$ emission and increases the energy efficiency.
\end{abstract}

Index Terms-Debutanuzer, energy, RSM, optimization.

\section{INTRODUCTION}

In the light of the emissions associated with fossil fuel combustion and their associated health and environmental impacts, natural gas is becoming increasingly attractive when compared with other fuels. Natural Gas Liquids (NGL) are commonly defined as heavier hydrocarbon liquids of natural gas. They are mainly composed of propane, butane and sometimes ethane. The separation of NGL in gas processing is energy intensive, which is performed by a series of three columns namely deethanizer, depropanizer and debutanizer [1]. The later is used to separates butane $\left(\mathrm{C}_{4}\right)$ cuts and lighter components from NGL, typically gasoline. In previous work, modelling and optimization of the distillation column of NGL fraction are studied, especially, for the two first columns [2]. The energy efficiency of the distillation columns was realized, by testing the effects of reflux ratio and column pressure on deethanizer and depropanizer

Manuscript received November 20, 2020; revised April 12, 2021.

Ahmed Ould Brahim and Souad Abderafi are with Mohammadia School of Engineering, Mohammed V University in Rabat, Ibn Sina, B.P. 765, Agdal, Rabat, 10090, Morocco (e-mail: ahmed.ouldbrahim0101@gmail.com, abderafi@emi.ac.ma). columns. The most widely used separation technique is the distillation considered as important separation unit in the chemical and process industries [3]. Its inconvenience is the energy intensive that accounts for more than $70 \%$ of the whole industrial energy consumption [4]. Generally, different methods were conducted by many researchers to optimize energy consumption of distillation column. Kiss et al. [5] have suggested energy efficient distillation technologies to make the right choice for a given separation task at early design stages [6]. Recently, Tavan et al. [7] used RSM and desirability function to investigate the effect of temperature, operating pressure and the feed inlet stage on the deethanizer column of new retrofitted plant. Concerning the optimization of the debutanizer column, we distinguished only the work realized by Jana and Mali that consists into examining the concept of internal heat integration [8]. Despite the improvement of the energy consumption made by this method, it remains expensive by requiring the purchase of new equipments.

This study is devoted to optimize the distillation column of NGL fractions, especially the debutanizer column. We opt for RSM coupled with desirability function to test the effect of important parameters such as reflux ratio and head pressure on the energy consumption and operating cost of debutanizer column. After description of studied process and modelling equations, the optimisation methodology will be presented. Before concluding, we give and we analyze the different results obtained.

\section{PROCESS Modeling AND VALIDATION}

\section{A. Debutanizer Column}

This work is related to an important unit operation in petroleum and NGL separation plant known as debutanizer column. This column is considered as the main column used to separate butane from the NGL product containing C3-C7 hydrocarbons [9]. Debutanizer column is equipped with 30 stages, a condenser and a reboiler as described in [10]. The feed of the column derived from the depropanizer is composed of traces of $\mathrm{C} 3$, amounts of the hydrocarbon type, $\mathrm{C} 4$ and $\mathrm{C} 5+$. This mixture feed the Debutanizer column with total mole flow equal to $142.4 \mathrm{k} \mathrm{mol} / \mathrm{h}$, at stage 16 that minimizes reboiler duty. The separation in the debutanizer is performed between the butane and the gazoline with a reflux ratio of 2.2 at $322 \mathrm{~K}$. At the top of this column, the butane (iC4/nC4) is obtained at 7.1atm and in the bottom a cut of gasoline, containing hydrocarbon chains type $\mathrm{C} 5+$. Subsequently, the downstream deisobutanizer column separates isobutane (iC4) from normal butane ( $\mathrm{nC} 4)$, because 
of the lowest volatility of iC4/nC4. Feed industrial data of debutaniser column are regrouped in Table I.

TABLE I: INDUSTRIAL DATA OF DEBUTANISER COLUMN [10]

\begin{tabular}{lccc}
\hline \hline & Parameters & Component & Mol fraction \\
\hline Trays number & 30 & $\mathrm{C} 3$ & 0.0010 \\
Feed tray position & 16 & i-C4 & 0.2597 \\
Reflux ratio & 2.2 & n-C4 & 0.3027 \\
Feed flow rate, F & 142.4 & i-C5 & 0.1517 \\
(kg.mol/h) & 398.4 & nC5 & 0.1147 \\
Feed temperature (K) & 17.50 & nC6 & 0.1147 \\
Feed pressure, P (atm) & 7.1 & nC7 & 0.0555 \\
P $_{\text {Head }}($ atm) & \multicolumn{3}{l}{} \\
\hline \hline
\end{tabular}

\section{B. Model and Validation}

The model equations that govern the operation of the separation column are obtained by using the equations of mass and energy balances, the summation equations, as well as the Vapor-Liquid Equilibrium (VLE) equations, as described by Tgqrguifa et al. [11]. The thermodynamic model like an equation of state (EOS) is required for VLE calculation. Among the many cubic EOS of Van der Waals type currently available, the equation proposed by Peng and Robinson (PR) is widely used due to its simplicity and flexibility, for hydrocarbons fractions [12], [13]. For extending PR EOS to mixtures, it is necessary to include composition. Many algebraic relations have been suggested for this purpose. We elected to choose those recommended for PR EOS [14]. Somme assumptions are followed for modeling the separation column. It consist that all trays are in equilibrium; the pressure in the column is constant; the heat loss of the column is negligible; total condensing and the composition and molar enthalpy changes of the saturated liquids and vapors over the feed stage are negligible. The simulation of the debutanizer column was carried out by using the feed conditions data of NGL separation and the model equations described above. This simulation was performed using the simulator COCO flowsheeting, coupled with Chemsep LITE column simulator [15]. Based on data of Table I, the temperatures and pressures at the bottom and head of the column, the energy of condenser and reboiler, and purity of butane were carried out. The calculated values were compared to experimental one, obtained from the literature [10]. This comparison is made by calculating the relative error (E). The results obtained are regrouped in Table II.

TABLE II: COMPARISON OF EXPERIMENTAL AND CALCULATED PARAMETERS VALUES, OF NGL SEPARATION

\begin{tabular}{lccc}
\hline \hline & $\mathrm{V}_{\mathrm{e}}$ & $\mathrm{V}_{\mathrm{c}}$ & $\mathrm{E}(\%)$ \\
\hline $\mathrm{T}_{\text {Bottom }}(\mathrm{K})$ & 394.6 & 394.77 & 0.04 \\
$\mathrm{~T}_{\text {Head }}(\mathrm{K})$ & 322.0 & 331.00 & 2.80 \\
$\mathrm{P}_{\text {Bottom }}(\mathrm{atm})$ & 7.400 & 7.3760 & 0.32 \\
$\mathrm{P}_{\text {Head }}(\mathrm{atm})$ & 7.100 & 7.1000 & 0.00 \\
Purity $(\mathrm{C} 4, \mathrm{iC} 4)$ & 0.9959 & 0.9937 & 0.22 \\
$\mathrm{E}_{\mathrm{r}}(\mathrm{kW})$ & 1020 & 1000 & 1.96 \\
$\mathrm{E}_{\mathrm{c}}(\mathrm{kW})$ & 1301 & 1300 & 0.08 \\
\hline \hline
\end{tabular}

This table indicates that the obtained errors between experimental values and calculated one are not exceed $3 \%$. The mean absolute error is equal to $0.87 \%$. These results allow us to conclude that the model is reliable and can be used for the energy optimization of debutanizer column.

\section{OPtimizATION METHOdOLOGY}

In this work, we seek to optimize energy consumption of the debutanizer column. There are different methods that can be used to optimize the distillation process as described recently by Tgarguifa et al. [11]. Comparison of the different methods shows that the Reponse Surface Methodology (RSM) is the simplest method compared to heat integration and mathematical methods. But when it tested to investigate the oil production process, RMS method presents several deficiencies and has to be improved [16]. An optimization procedure based on a desirability function approach can be coupled to the RSM, for better resolution of problem. In this section, we describe the procedure followed for this approach, to optimize the debutanizer process.

\section{A. Response Surface Method}

The RSM is a statistical method, generally used to analyze experimental data, or numerically data obtained, by simulation [17]. This method consists to carry out an empirical modeling which connects the output variables to the input variables using a quadratic equation, having the following form:

$$
Y=a_{0}+\sum a_{i} x_{i}+\sum a_{i i} x_{i i}^{2}+\sum \sum a_{i j} x_{i} x_{j}
$$

To adjust the coefficients of equation (1), numerical simulation studies are used, because the experimentation on a real process is not always practical or impossible, and the resulting costs are very high without being able to predict his behavior during or after the experiment. Numerical simulation data can be obtained following one of experimental design method [17]. Hence the significant factors of coefficients are determined using Multiple Linear Regression (MLR). The later is a statistical learning mechanism used to explain the behavior of one dependent variable as a function of many others predictor variables named explanatory variables [18]. It allows finding the best model between dependent and predictor variables. Several numerical simulation studies have been successfully used to understand the experimental changes in economic terms, and to model industrial processes. This tool makes possible to estimate the effect of changes in stream composition, changes in the operating conditions, process configurations, integration of the treatment steps, or the use of new technologies. The use of the methods of experimental design and statistical tools allows working with a response surface approach instead the operating point.

\section{B. Desirability Function}

The desirability function method was developed to optimize the responses and determine the exact optimal values with their coordinates [19]. This method was based on the transformation of all the responses obtained from different scales of measurement to an identical scale of desirability and dimensionless. The values of the desirability functions, $d_{i}$ are between zero and one. Where, 0 stands for rejection of the response and 1 stands for an excellent 
response. The equation for calculating the individual desirability values can thus be presented:

$$
d_{i}\left(Y_{i}\right)= \begin{cases}0 & \Leftrightarrow Y_{i} \leq Y_{i, \text { min }} \\ {\left[\frac{Y_{i}-Y_{i, \text { min }}}{Y_{i, \max }-Y_{i, \text { min }}}\right]^{r_{i}}} & \Leftrightarrow Y_{i, \min } \leq Y_{i} \leq Y_{i, \max } \\ 1 & \Leftrightarrow Y_{i} \leq Y_{i, \max }\end{cases}
$$

where, $Y_{i, \text { min }}$, the value below which the response $\mathrm{Y}_{\mathrm{i}}$ is not suitable $\left(d_{i}=0\right) ; Y_{i, \max }$, the target value above which the response $Y_{i}$ is very satisfactory $\left(d_{i}=1\right) ; r_{i}$, the factor modifying the importance of an increase in the $Y_{i}$ response for the individual desirability considered. This corresponds to the weighting of the factor depending on the user as a function of the desired degree of desirability for a given response between $Y_{i, \min }$ and $Y_{i, \max }$.

The individual desirability, $d_{k}(k$, indicates the number of responses) is then combined using the geometric mean, which gives the overall desirability $\mathrm{D}$. The corresponding equation is as follow:

$$
D=\sqrt[k]{\left(d_{1}\left(Y_{1}\right) \times d_{2}\left(Y_{2}\right) \times \ldots \ldots \ldots \ldots \ldots \times d_{k}\left(Y_{k}\right)\right)}
$$

Our objective here is to test the effect of reflux ratio and pressure variations on energy consumption of the studied process.

\section{Factor Coding and Experimental Design}

To perform the simulation of the LNG separation column, all the operating parameters of the column are kept fixed, with the exception of the reflux ratio (RR) and the pressure, which makes it possible to test their effects on the energy consumption of reboiler and condenser, as well as purity. Therefore, the reflux ratio was varied between 1.1 and 2.53; and the pressure between 5.3 and $8.23 \mathrm{~atm}$. These operating parameters do not have the same dimensions, which makes it difficult to compare their coefficients. Normalized (or coded) values are used. Table III shows the variables coded for the reflux ratio and the pressure. This coding method can increase the accuracy of the models in order to obtain homogeneous equations and simple calculation procedures. Note, however, that statistical models can only be used in the operating variable ranges used; no extrapolation is allowed.

TABLE III: COMPARISON OF EXPERIMENTAL AND CALCULATED PARAMETERS VALUES, OF NGL SEPARATION

\begin{tabular}{ccccc}
\hline \hline Parameter & $\mathrm{X}_{\mathrm{i}}$ & -1 & 0 & 1 \\
\hline $\mathrm{RR}$ & $\mathrm{X}_{\mathrm{RR}}$ & 1.1 & 1.819 & 2.53 \\
$\mathrm{P}(\mathrm{atm})$ & $\mathrm{X}_{\mathrm{P}}$ & 5.3 & 6.765 & 8.23 \\
\hline \hline
\end{tabular}

According to the central composite design chosen, changes in this area is to choose the axial values on the faces and set just one focal point instead because all variables are determinists in the case of numerical experience design. In this case the values generated by the experimental design are equal to 9 experiments. By following this numerical experimental plan, the calculation of the condenser and reboiler energy as well as the purity was performed by simulation. This calculation was done by using the model validated above for the debutanizer column. The data on the feed conditions for the separation of LNG required for this calculation were used. The simulation results obtained are summarized in Table IV.

TABLE IV: PURITY AND ENERGY CONSUMPTION OF THE REBOILER AND

\begin{tabular}{cccccc}
\multicolumn{5}{c}{ CONDENSER } \\
\hline \hline $\mathrm{N}^{\circ}$ Simulation & $\mathrm{RR}$ & $\mathrm{P}$ & $\mathrm{E}_{\mathrm{C}}(\mathrm{MW})$ & $\mathrm{E}_{\mathrm{R}}(\mathrm{MW})$ & Purety \\
\hline 1 & -1 & 0 & 0.88 & 0.58 & 0.9200 \\
2 & -1 & 1 & 0.8 & 0.6 & 0.9200 \\
3 & 0 & -1 & 1.2 & 0.8 & 0.9900 \\
4 & 1 & 0 & 1.4 & 1.2 & 0.9970 \\
5 & 0 & 0 & 1.1 & 0.9 & 0.9930 \\
6 & 0 & 1 & 1.1 & 0.9 & 0.9880 \\
7 & 1 & -1 & 1.5 & 1.1 & 0.9980 \\
8 & -1 & -1 & 0.9 & 0.5 & 0.9300 \\
9 & 1 & 1 & 1.4 & 1.2 & 0.9970 \\
\hline \hline
\end{tabular}

\section{RESUlTS AND DISCUSSION}

Data of Table IV were fitted to the Eq. (1), using multiple linear regression. The stepwise regression was tested based on forward selection and backward elimination techniques with Bayesian information criterion, to estimate the model coefficients. Statistical tests were used to identify all terms of developed models with $95 \%$ confidence interval. The model reliability was verified based on the small mean square error, in our case, the same value of the mean square error was obtained for each regression.

\section{A. Statistical Models}

Three prediction models for purity and Energy of the reboiler and condenser, for the separation column were obtained. The statistical results of these three models are summarized in Table V.

\begin{tabular}{|c|c|c|c|c|c|c|}
\hline & $\mathrm{Ec}$ & $\mathrm{Er}$ & $\mathrm{Pu}$ & Ec & $\mathrm{Er}$ & $\mathrm{Pu}$ \\
\hline & \multicolumn{3}{|c|}{ Fisher test Prob $>F$} & \multicolumn{3}{|c|}{ Student test Prob $>|t|$} \\
\hline Const & & & & $<10^{-4}$ & $<10^{-4}$ & $<10^{-4}$ \\
\hline $\mathrm{X}_{\mathrm{RR}}$ & $10^{-4}$ & $10^{-4}$ & $10^{-4}$ & $<10^{-4}$ & $<10^{-4}$ & $<10^{-4}$ \\
\hline $\mathrm{X}_{\mathrm{HP}}$ & $7.10^{-4}$ & $10^{-4}$ & $10^{-4}$ & $<10^{-4}$ & $<7.10^{-4}$ & 0.068 \\
\hline $\mathrm{X}_{\mathrm{RR}} \times \mathrm{X}_{\mathrm{HP}}$ & 1 & 1 & 1 & 1 & 1 & 0.110 \\
\hline $\mathrm{X}_{\mathrm{RR}}^{2}$ & 0.150 & 0.15 & 0.15 & 0.15 & 0.154 & $<10^{-4}$ \\
\hline $\mathrm{X}_{\mathrm{HP}}^{2}$ & 0.050 & $10^{-4}$ & $10^{-4}$ & $<10^{-4}$ & 0.050 & 0.631 \\
\hline
\end{tabular}

TABLE V: Statistical RESUlts OF THE CONDENSER HeAt DUTy MODEL

According Student test, the significance of the model factors were checked, for degree of freedom equal to 6 and a risk of error, $\alpha$ equal to 0.05 . The factor is significant if $t_{\text {critical }}$ is less than t, knowing $t_{\text {critical }}$ equal to 2.776. Hence, it can be observed that the $X_{R R} \times X_{H P}, X_{R R}$ and $X_{H P}$ are not statistically significant. Then the model factors were examined using the Fisher test, comparing $\mathrm{F}$ of each factor with $F_{\text {critical }}$, which is equal to 7.71. The results indicate that $X_{R R}$ and $X_{H P}$ factors are dependents in all models. The correlation coefficient and the mean square error of the fitted model were obtained with a value equal to 0.9930 and $2.15 \times 10^{-2}$, for condenser energy and 0.9999 and $0.5 \times 10^{-2}$, for reboiler energy and to 0.9960 and $0.25 \times 10^{-2}$, for purity. The fitted models are given by equations 4,5 and 6 :

$$
\begin{gathered}
E_{C}=1.105+0.286 X_{R R}-0.05 X_{H P} \\
E_{R}=0.89+0.303 X_{R R}+0.05 X_{H P}-0.045 X_{H P}^{2}
\end{gathered}
$$




$$
P u=0.99+0.0379 X_{R R}-0.0312 X_{R R}^{2}
$$

The validity of the fitted models was also verified by comparing the correlation coefficient of the models with the critical correlation coefficient $\mathrm{R}_{\text {critical }}$, which equal to 0.811 . The comparison result confirmed the reliability of the all developed models. Fig. 1 presents the profiling isoresponse and the response surface of the condenser energy, reboiler energy and purity in terms of reflux ratio and head pressure.
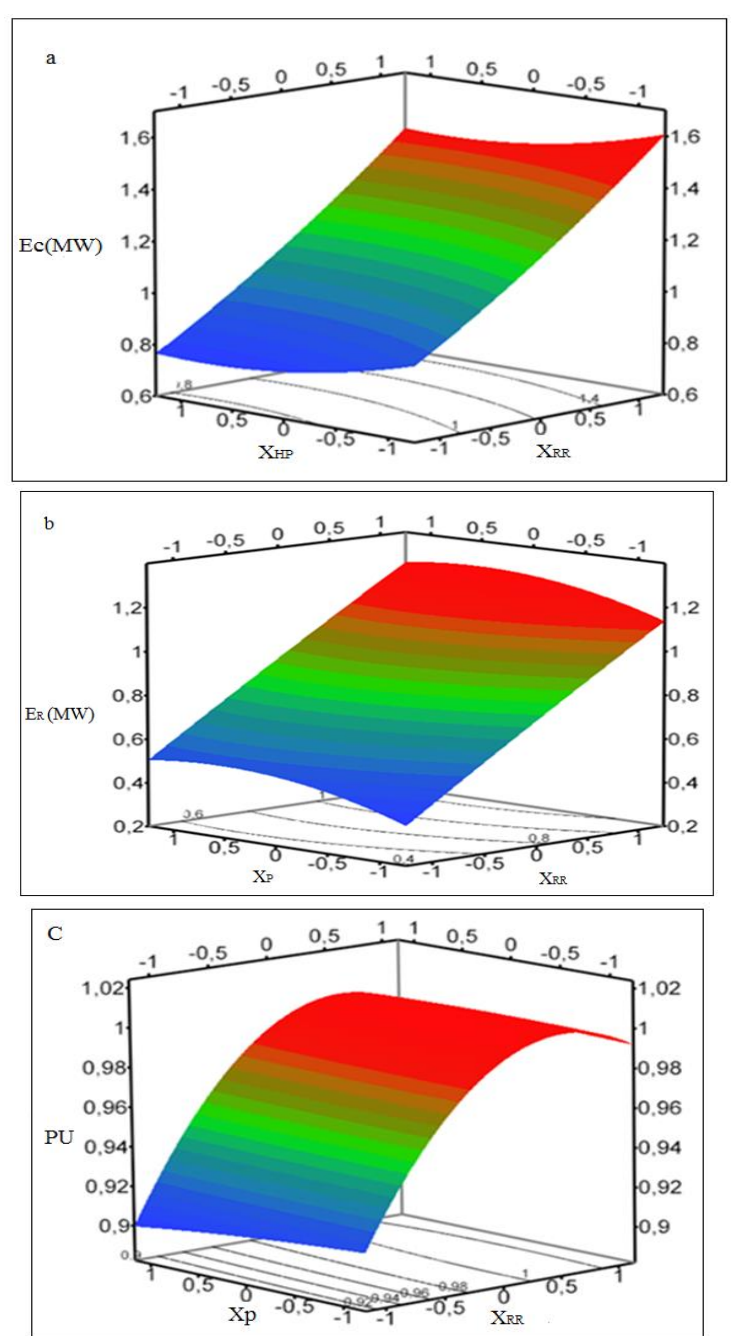

Fig. 1. Response surface depending on reflux ratio and pressure for (a) condenser duty, (b) Reboiler duty and (c) purity.

These figures indicate that the reflux ratio has a great effect on the energy and purity, compared to the head pressure. Note also that the energy greatly decreases at the boundary values of head pressure, for low reflux ratio.

\section{B. The Optimal Values}

The desirability function method was followed to optimize the responses and to accurately determine the optimal values with their coordinates [19]. The statistical models obtained were used with the desirability function. The reflux ratio and the pressure at the top of the column were used as search variables, to minimize the energy consumption of the condenser and the reboiler and taking into account the purity of the butane, as a constraint equal to 0,99. Table VI shows the results obtained for the optimal values of the operating parameters and the desirability function. This table shows that the highest value of the desirability function tend to 1 , indicating that the optimal values obtained are reliable. At this value the desirability function corresponds to the coded values -0.720 and -1 , for the reflux ratio and the pressure, respectively. From these values we deduce the actual values 1.15 for the reflux ratio and $5.3 \mathrm{~atm}$ for the pressure. The minimum consumption of the condenser is equal to 0.984 MW and that of the reboiler is equal to $0.614 \mathrm{MW}$.

TABLE VI: OPTIMUM VALUES OF THE OPERATING PARAMETERS AND THE

\begin{tabular}{lllll}
\multicolumn{5}{c}{ DESIRABILITY FUNCTION } \\
\hline \hline Parameters & $\mathrm{RR}$ & $\mathrm{P}(\mathrm{atm})$ & $\mathrm{E}_{\mathrm{C}}(\mathrm{MW})$ & $\mathrm{E}_{\mathrm{R}}(\mathrm{MW})$ \\
\hline Optimal values & 1.15 & 5.3 & 0.984 & 0.614 \\
\hline Desirability $(\%)$ & & \multicolumn{5}{c}{99.35} \\
\hline \hline
\end{tabular}

\section{Energy and Cost Evaluation}

Following this optimization method, the minimum energy and their optimum parameters coordinates were determined, with high value of desirability function equal to $99 \%$. The optimal values obtained are 1.15 and 5.3 atm for the reflux ratio and head pressure, respectively. The operating energy of the debutanizer column was calculated before and after optimization process, using the corresponding heat duty of condenser and reboiler. The obtained results are presented in the Fig. 2. The total operating energy of the debutanizer column before and after optimization is equal to $0.486 \mathrm{kWh} / \mathrm{Kg}$ and $0.320 \mathrm{kWh} / \mathrm{Kg}$, respectively. The operating cost of the debutanizer column is calculated as the sum of operating costs of the condenser and reboiler [11]. Required energy cost of the condenser was generated by electricity and that of the reboiler by heat steam. These two energy resources were used to calculate the total operating cost of the column. The employed energy cost of steam generation was estimated equal to $0.028 \$ / \mathrm{kWh}$. This estimation was based on the average price of industrial fuel, in September 2017, according to the International Energy Agency [20]. For the electricity cost, its value was equal to $0.0672 \$ / \mathrm{kWh}$; it was obtained from US Energy information administration, in October 2017 [21]. The results of operating energy and costs are presented in Fig. 2. Fig. 2 (a) shows a comparison between the energy consumed by the debutanizer column and that which can be consumed after optimization and Fig. 2 (b) shows a comparison between the cost of debutanizer column obtained before and after optimization. The total operating cost of debutanizer column equal to $0.0245 \$ / \mathrm{Kg}$ is reduced to $0.0181 \$ / \mathrm{Kg}$, after optimization. This represents a saving in the total operating cost of the optimized process equal to $26.14 \%$, producing butane with purity equal to $99 \%$.

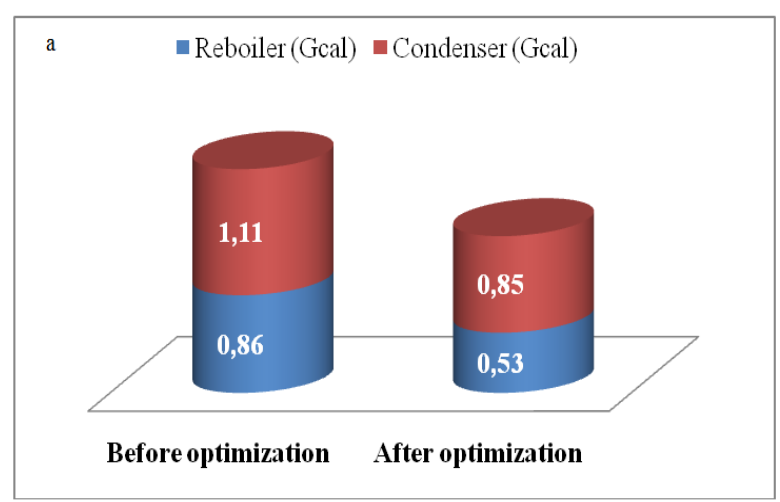




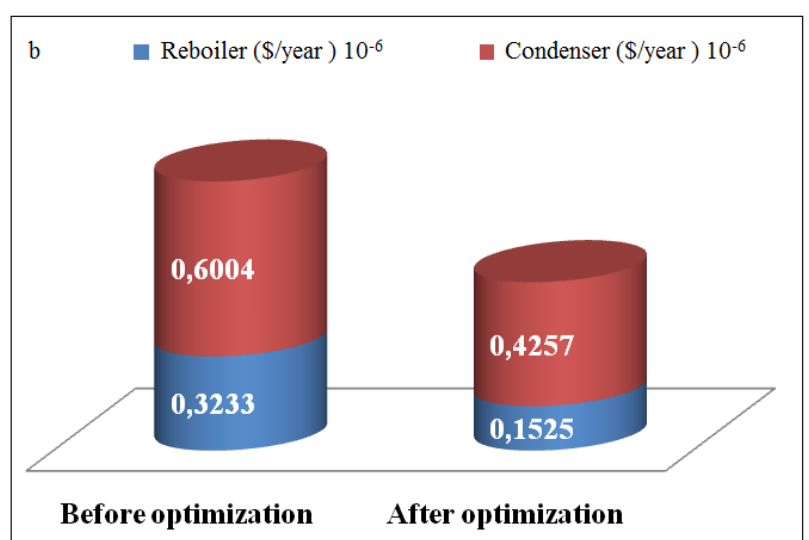

Fig. 2. Operating energy (a) and operating cost (b), of the debutanizer column before and after optimization.

\section{Calculation of $\mathrm{CO}_{2}$ Emissions}

In distillation column such as NGL distillation units, $\mathrm{CO}_{2}$ is generated mainly from boilers or furnaces. These devices are used to provide a heat and power to the process by burning a fuel. The fuel is combusted when mixed with air, producing only $\mathrm{CO}_{2}$. The heat and power generating devices used are fired heater (furnace) and boiler; so this device is source of $\mathrm{CO}_{2}$ emissions. Typical fuels used in this heating device are light and heavy fuel oils, and natural gas. In the combustion of fuels, air is assumed to be in excess to ensure complete combustion, so that no carbon monoxide is formed. The concentration of $\mathrm{CO}_{2}$ emissions (in $\mathrm{kg} / \mathrm{s}$ ), is related to the amount of fuel burnt, $\mathrm{Q}_{\text {Fuel }}$ in a heating device [2]. Hence, the optimal value obtained was used to determine $\mathrm{CO}_{2}$ emissions. Fig. 3 shows the variation of $\mathrm{CO}_{2}$ emissions according to the amount of reboiler heat for the debutanizer. Comparing these results shows a reduction of $38 \%$, which indicate the improvement of greenhouse gas emissions.

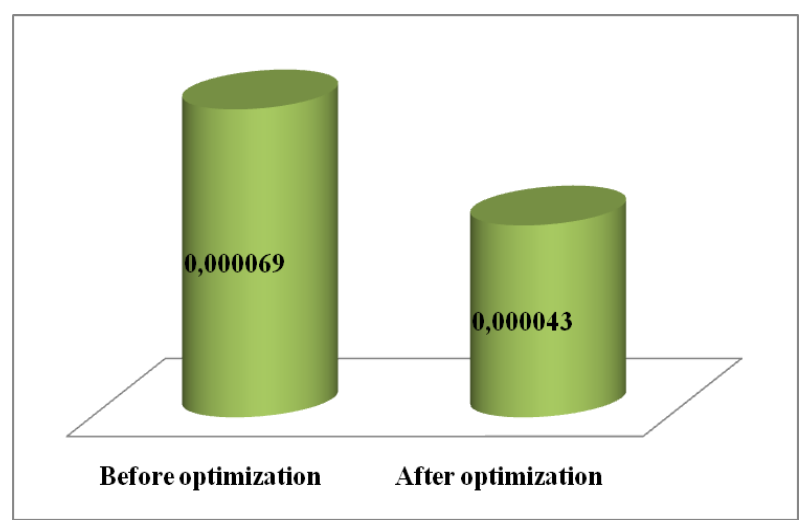

Fig. 3. Concentration of greenhouse gases in $(\mathrm{kg} / \mathrm{s})$, for the debutanizer, before and after optimization.

\section{CONCLUSION}

This study is devoted to energetic optimization of debutanizer column in the NGL plant. For optimization, required PR EOS was validated successfully to reproduce experimental data of industrial plant with mean absolute error equal to $0.87 \%$. Thereafter, the response surface methodology coupled to desirability function was applied to optimize the operating conditions of the industrial process. Hence, three models were developed to express the heat duty of condenser and reboiler, and the purity of butane, in function on the reflux ratio and head pressure of the debutanizer column. The reliability of these models was assessed via a set of statistical analyses. This optimization step allowed us to define the optimal values of reflux ratio and head pressure, with desirability function equal to $99 \%$. Under the determined operating conditions optimal values, operating energy and cost of the industrial process were reduced respectively by $38 \%$ and $37 \%$, and besides, a high purity of butane was noticed reaching $99 \%$. These results showed, also the improvement of greenhouse gas emissions, by $38 \%$.

\section{CONFLICT OF INTEREST}

The authors declare no conflict of interest.

\section{AUTHOR CONTRIBUTIONS}

A. Ould Brahim conducted the research, under the direction of S. Abderafi who analyzed the results and wrote the article. All authors had approved the final version.

\section{ACKNOWLEDGMENT}

The authors gratefully acknowledge support provided by Moroccan Petroleum refinery SAMIR.

\section{REFERENCES}

[1] H. Haitao and J. B. Riggs, "Comparison of PI and MPC for control of a gas recovery unit," Journal of Process Control, vol. 12, pp. 163-173, 2002 .

[2] A.O. Brahim and S. Abderafi, "Optimisation of the energy efficiency and the CO2 reduction, for the NGL separation," in Proc. International Renewable and Sustainable Energy Conference, 2016.

[3] A. Gorak and E. Sorensen, Distillation Fundamentals and Principles, 1st ed. Academic press, San Diego, 2014.

[4] C. Li, X. Zhanga, S. Zhanga, and K. Suzukib, "Environmentally conscious design of chemical processes and products: Multi-optimization method," Chemical Engineering Research and Design, vol. 87, pp. 233-243, 2009.

[5] A. K. Anton, J. Servando, L. Flores, A.Carlos, and F. Infante, "Towards energy efficient distillation technologies - Making the right choice," Energy, vol. 47, pp. 531-542, 2012.

[6] H. Shahandeh, J. Ivakpour, and N. Kasiri, "Internal and external HIDiCs (heat-integrated distillation columns) optimization by genetic algorithm," Energy, vol. 64, pp. 875-886, 2014.

[7] Y. Tavan, S. H. Hosseini, and A. Kargari, "An increased production capacity by a retrofitted industrial deethanizer column," Journal of Natural Gas Science and Engineering, vol. 30, pp. 248-255, 2016.

[8] A. K., Jana and S. V. Mali, "Analysis and control of a partially heat integrated refinery debutanizer," Computers and Chemical Engineering, vol. 34, pp. 1296-1305, 2010.

[9] A. K. Jana, "Chemical process modelling and computer simulation (1st ed.)," New Delhi: Prentice-Hall, pp. 279-298, 2008.

[10] W. L. Luyben, "Control of a train of distillation columns for the separation of NGL," Ind Eng Chem Res, vol. 52, pp. 10741-10753, 2013.

[11] A. Tgarguifa, S. Abderafi, and T. Bounahmidi, "Energetic optimization of Moroccan distillery using simulation and response surface methodology," Renewable and Sustainable Energy Reviews, vol. 75 , pp. 415-425, 2017.

[12] M. Mokarizadeh, S. Haghighi, and D. Mowla, "Energy optimization for liquefaction process of natural gas in peak shaving plant," Energy, vol. 3, pp. 2878-2885, 2010.

[13] X. G. Liu. C. He. C. C. He. J. J. Chen. B. J. Zhang. And Q. L. Chen, “A new retrofit approach to the absorption-stabilization process for improving energy efficiency in refineries," Energy, vol. 118, pp. 1131-1145, 2017.

[14] J. M. Prausnitz, R. N. Lichtenthaler, and E. G. Azevedo, Molecular Thermodynamics of Fluid-Phase Equilibria, 3rd ed. Prentice-Hall, New Jersey, 1999. 
[15] CAPE-OPEN Flowsheeting Environment, COFE Version 3.0.0.5, 2014.

[16] D. Bas and I. H. Boyac, "Modeling and optimization I: Usability of response surface methodology," Journal of Food Engineering, vol. 78, pp. 836-845, 2007.

[17] H.Wang, X. Cui, R.. Li, and C. Wang, “ Response surface optimization of the operating parameters for a complex distillation column based on process simulation," Energy Procedia, vol. 16, pp. 571-578, 2012.

[18] A. G. Ryan, G. G. Vining, E. A. Peck, D. C. Montgomery, and A. G. Ryan, Solutions Manual to Accompany Introduction to Linear Regression Analysis, 5th Edition, John Wiley \& Sons, 2013.

[19] E. C. Harrington, "The desirability function," Industrial Quality Control, pp. 494-498, 1965.

[20] Electricity_Information. (2017). [Online]. Available: http://www.iea.org/bookshop/727-Electricity_Information_2016

$\begin{array}{llll}\text { [21] Petroleum. (2017). [Online]. Available: } & \end{array}$ https://www.eia.gov/petroleum/data.php\#prices

Copyright $\odot 2021$ by the authors. This is an open access article distributed under the Creative Commons Attribution License which permits unrestricted use, distribution, and reproduction in any medium, provided the original work is properly cited (CC BY 4.0).

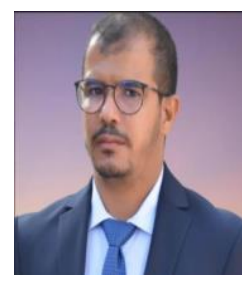

Ahmed Ould Brahim is Ph.D, freshly graduated from Mohammadia Engineering School attached to Mohammed V University in Rabat. He had his master in industrial process and sustainable development, from Sciences Faculty of Rabat and licence in chemistry from Faculty of Sciences and Technology, in Nouakchott-Mauritania. Research interests include modeling and optimization.

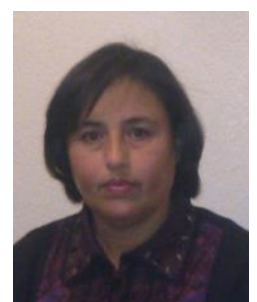

Souad Abderafi Abderafi is professor at Moroccan school of engineering, where she received her doctorate $(\mathrm{PhD})$ in chemical engineering. She is currently teaching at Mohammadia Engineering School attached to Mohammed V University in Rabat. Her main research interests are industrial process modeling and optimization; renewable energy (solar energy and biomass), energetic efficiency. Digital identifier of Abderafi is Research Gate (https://www.researchgate.net/profile/S_Abderafi), and her full ORCID $\mathrm{iD}$ and the link to her public record is https://orcid.org/0000-0001-9534-6941. 